\title{
Modified onlay technique for the repair of the more complicated incisional hernias: single-centre evaluation of a large cohort
}

\author{
M. M. Poelman • B. L. A. M. Langenhorst • \\ J. F. Schellekens $\cdot$ W. H. Schreurs
}

Received: 4 August 2009/Accepted: 15 February 2010/Published online: 14 March 2010

(C) The Author(s) 2010. This article is published with open access at Springerlink.com

\begin{abstract}
Background The repair of incisional hernias remains a challenge for the general surgeon. Indications for surgery are severe bowel obstruction, as well as aesthetic problems. There are various surgical methods to correct these hernias, with varying results. However, the gold standard has not yet been found. Both laparoscopic repair and the component separation technique (CTS) have proven to be acceptable techniques; however, they are not always suitable for resolving the more complicated abdominal wall defects, i.e. after open-abdomen treatment or fascial necrosis. In our hospital, we developed a new onlay technique which we have evaluated in the following research. Patients and methods During a period of 10 years (19962007), 101 patients with an incisional hernia were corrected with the new onlay technique. A Marlex mesh of dimensions at least $10 \times 20 \mathrm{~cm}$ was used, overlapping the fascia by at least $5 \mathrm{~cm}$ on each side. This mesh was stapled onto the fascia with skin staples. Of the 101 patients, there were 45 men and 56 women, with a mean age of 55 years. Nine patients died and 13 were lost during follow-up. Of the remaining 79 patients, eight refused to participate. The mean follow-up time was 64 months (normal distribution, standard deviation [SD] 34 months). This cohort of 101 patients was studied retrospectively.

Results Seventy-one of the 101 patients were evaluated at our out-patient clinic. For 24 patients (25\%), the operation was for a recurrence after an incisional hernia correction in the past. Twenty-one patients (20\%) had an open-abdomen
\end{abstract}

M. M. Poelman $(\bowtie)$ · B. L. A. M. Langenhorst .

J. F. Schellekens - W. H. Schreurs

Department of Surgery, Medical Centre Alkmaar,

Wilhelminalaan 12, 1815 JD Alkmaar, The Netherlands

e-mail: m.m.poelman@mca.nl treatment in their medical history. The surgical procedure was technically possible in all patients and the mean operation time was $63 \mathrm{~min}$. The median admission time was 4.5 days (quartiles 3-6.25). The mean follow-up time was 64 months (SD 35 months). A seroma was reported in 27 of 101 patients $(27 \%)$ and a wound infection in 22 patients $(21 \%)$, of which seven patients had to be reoperated. Only if a patient was evaluated at our out-patient clinic could reherniation have been scored; this occurred in 11 of 71 patients $(16 \%)$.

Conclusion This technique is an effective and simple procedure to correct incisional hernias with acceptable complication rates and is feasible even in the more complicated hernias.

Keywords Incisional hernia - Abdominal wall defects . Mesh repair · Hernia

\section{Introduction}

Incisional hernias are a frequent complication after abdominal surgery, with an incidence of $10-23 \%$ [1, 2]. Although these hernias can be treated conservatively (with techniques like a bodice), frequently, there are reasons to correct them surgically. Incisional hernias enlarge over time, cause pain and/or aesthetic complaints. They can cause serious complications like bowel obstruction due to incarceration or strangulation. Patients suffer from these hernias and their quality of life as well as their chances for employment are reduced [3]. Improvement of the quality of life is the major reason to seek surgical care [4-6].

Incisional hernia surgery is still a challenge for the general surgeon. Repair of these hernias comes with a high recurrence rate, high morbidity and, therefore, high costs. 
Frequent complications are reherniation, seroma formation and wound infection [7, 8]. Many techniques have been studied, but the gold standard has not yet been found [2, 3, 9]. This is probably, at least partially, due to the multifactorial aetiology of incisional hernias. Failures of the surgical technique, deterioration of the patient's nutritional status, as well as interpersonal factors contribute. Reherniation rates of $0-36 \%$ have been reported, even after mesh repair $[3,7,8,10]$. There is no evidence that laparoscopic repair has a lower recurrence rate compared to open repair $[11,12]$ and a recent Cochrane analysis states that there is insufficient evidence as to which mesh position or which type of mesh should be used [3].

Most challenging are, of course, the large and/or the complicated hernias. There is no superior technique and the overall results in all series are, at best, moderate. In this article, we report a new technique, an onlay polypropylene mesh fixed with multiple skin staples. A single-centre retrospective study was performed.

\section{Methods}

\section{Patients}

All patients who had an incisional hernia operation between January 1996 and January 2007 were selected. Out of this group, the patients who were operated using an onlay polypropylene mesh with a minimum size of $10 \times 20 \mathrm{~cm}$ fixed with skin staples were included in this study. This onlay technique was only used when a large, complicated hernia was present. Smaller, simple hernias were corrected using laparoscopy or open techniques.

Surgical procedure

All operations are performed under general anaesthesia. Patients are placed in the supine position with their arms tucked in at the sides. After disinfection, one doses of antibiotics was given prior to the start of the operation (cefuroxim 1,500 mg iv). The skin scar was sometimes excised and the subcutis opened. A de-epithelialisation was performed when the fascia was absent and the subcutis was spread until the borders of the remaining fascia were found. A plane of at least $5 \mathrm{~cm}$ was made in all directions over the fascia. The fascial edges were approximated as far as possible and closed using an absorbable Vicryl suture, putting the de-epithelialised part intra-abdominally without entering the abdominal cavity. After the hernia was successfully approximated and haemostasis was achieved, the Marlex mesh (Marlex ${ }^{\odot}$; C.R. Bard) was placed on the freed fascial edges and trimmed to fit. The mesh was never put directly on the intestines. Fascia, de-epithelialised tissue or omentum was always used to put in between the intestines and the mesh. The mesh was fixed with over 150 skin staples to the fascia (Figs. 1, 2). Two suction drains were placed on top of the mesh and the subcutis and skin were closed in layers.

\section{Follow-up}

All patients who were still alive were sent a letter to ask if they were willing to visit our out-patient clinic for an evaluation. Patients who opted not to participate were asked for what reason. This was then documented. After written consent was given, patients were invited to our outpatient clinic for an interview and physical examination of their abdomen. A recurrent hernia was diagnosed when a facial defect could be palpated when lifting the head from the examination table to raise the abdominal pressure. If this examination was not conclusive (in two patients), a computed tomography (CT) scan was performed.

Demographics as well as pre-, peri- and post-operative data were collected. Patient history and special features such as history of an open abdomen were noted. Postoperative outcomes were wound-edge necrosis, wound infection, fistulas, seromas, bleedings, re-admission and length of stay, re-operation, mortality and reherniation in the follow-up.

All of the data were entered into an SPSS database. All statistics mentioned are means or medians along with their extremes or are frequencies.

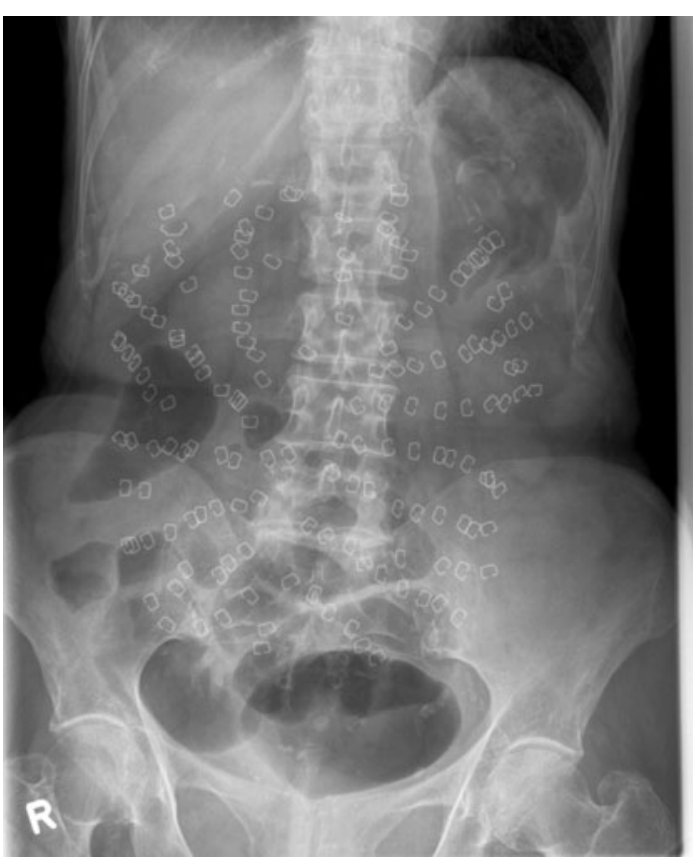

Fig. 1 X-ray of the abdomen of a person after incisional hernia correction with the new onlay technique 


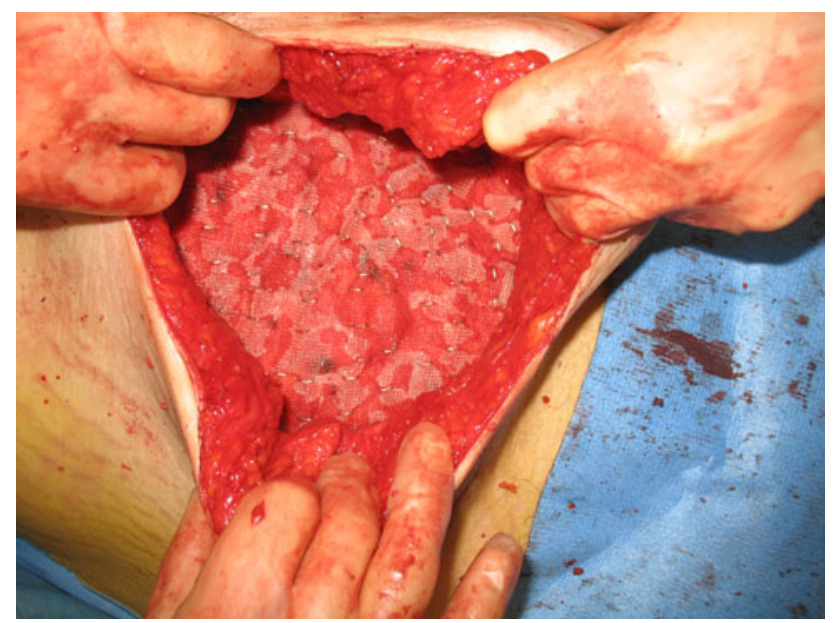

Fig. 2 The mesh is fixed with skin staples

\section{Results}

Patients

Between January 1996 and January 2007, 119 patients with incisional hernias were treated using this onlay technique. All of these patients except six were operated by the same two surgeons. These six patients were excluded from this study because it was not certain that exactly the same technique was used. In 12 patients, an attempt was made to correct the incisional hernia with the new onlay technique, but failed due to iatrogenic bowel lesions. Eventually, these hernias were not corrected with a mesh. This group was also excluded. In total, 101 patients were included.

The mean age at the time of operation was 55 years (normal distribution, standard deviation [SD] 14.4 years). There were $45(44 \%)$ males and $56(56 \%)$ females. Nine of these patients had died at the time of evaluation. These deaths were not related to the hernia correction. Thirteen patients were lost to follow-up. Eight patients refused to participate, three of them because they were dissatisfied and five because of logistic reasons. Therefore, it was possible to evaluate only 71 of the 101 patients in our outpatient clinic. Seroma formation, infection and co morbidity is reported using the files of all 101 patients. Recurrence was scored after the patients were seen in follow-up and is, therefore, only mentioned in the outpatient group $(n=71)$.

Indications for surgery were complaints of bowel obstruction, i.e. patients felt pain or had difficulties passing stool. Only a minority of the patients found the hernia aesthetically unacceptable.

The most prevalent comorbidity (Table 1) is obesity (mean body mass index [BMI] >29); 43 patients had a BMI of more than 29. Nineteen patients had a history of cardiovascular disease. There were 11 diabetes patients, 27
Table 1 Baseline characteristics of patients

\begin{tabular}{|c|c|c|c|c|c|}
\hline & $n(\%)$ & Mean & SD & Minimum & Maximum \\
\hline Gender & 56 (55) female & & & & \\
\hline Diabetes & $11(11)$ & & & & \\
\hline $\begin{array}{l}\text { Cardiovascular } \\
\text { disease }\end{array}$ & 19 (19) & & & & \\
\hline $\begin{array}{l}\text { Pulmonary } \\
\text { disease }\end{array}$ & 18 (18) & & & & \\
\hline Smokers & $27(27)$ & & & & \\
\hline $\begin{array}{l}\text { Use of } \\
\text { corticosteroids }\end{array}$ & $5(5)$ & & & & \\
\hline $\begin{array}{l}\text { History of open- } \\
\text { abdomen } \\
\text { treatment }\end{array}$ & $21(20)$ & & & & \\
\hline $\begin{array}{l}\text { ASA score at } \\
\text { time of } \\
\text { operation }\end{array}$ & & 1.8 & 0.6 & 1 & 3 \\
\hline BMI & & 29 & 9 & 19 & 48 \\
\hline
\end{tabular}

ASA American Society of Anesthesiologists risk score

patients smoked and five used corticosteroids. Seventy patients $(70 \%)$ developed an incisional hernia after a medial laparotomy. About 18 patients had a recurrent hernia after former incisional hernia repair using another technique. There were 21 patients $(20 \%)$ with a history of open-abdomen treatment.

The surgical procedure was technically possible in all patients and the mean operation time was $63 \mathrm{~min}$. The median admission time was 4.5 days (quartiles 3-6.25). The mean follow-up was 64 months (SD 34 months). During follow-up, 27 patients $(27 \%)$ were seen more frequently in the out-patient department because of a seroma. A wound infection was found in 22 patients (21\%). Seven of these patients had to be operated again: three with a seroma and a wound infection, two with only a seroma and two with only a wound infection. In the majority of cases, the patients with seromas and infections could be treated without surgical interference.

About six patients $(6 \%)$ suffered chronic pain and, in one case, the mesh had to be removed. Whether or not this resolved the pain is unknown because the patient was lost to follow-up. Most patients report pain or an unpleasant sensation when bending over, due to the stiffness of the mesh. None of them considered this invalidating. Migration of the material was not seen. Reherniation occurred in 11 patients $(16 \%)$ (Table 2$)$.

\section{Discussion}

Large abdominal wall defects are a challenge for surgeons. The incidence of incisional hernias is high and the surgical techniques to correct them challenging. Conditions 
Table 2 Complications

\begin{tabular}{lll}
\hline & $n(\%)$ & Surgical interference \\
\hline Seroma & $27(27)$ & 5 \\
Infection & $22(21)$ & 5 \\
Wound-edge necrosis & $17(17)$ & 0 \\
Recurrence & $11(16)$ & \\
Chronic pain & $6(6)$ & 1 \\
Re-admission & $15(15)$ & \\
Mortality & 0 & \\
Re-operation & $16(6)$ & 16 \\
Post-surgical complications & \\
\hline
\end{tabular}

${ }^{a}$ Non-procedure-related complications

associated with the development of incisional hernias are suture technique, wound infection, increased abdominal wall tension, metabolic connective tissue disorder and abdominal aortic aneurysms [1, 2, 7, 13].

In the last decade, a lot of research has been done to find the best method to resolve incisional hernias. Even in a large surgical department as ours, only 10 to 12 onlay procedures are performed annually, which makes it difficult to evaluate techniques by randomised controlled trials. What has been proven is that the use of a mesh to correct these hernias is necessary in order to avoid high recurrence rates $[2,3,7-10]$.

The component separation technique (CST) was first described by Ramirez [14] in 1990 to reconstruct the abdominal wall without the use of prosthetic material. It was first tested on cadavers and is based on enlarging the abdominal wall surface through the translation of muscular layers.

Several in vivo studies were performed after the introduction of the CST. In 2007, de Vries Reilingh wrote his thesis about the correction of large abdominal wall defects and studied a modified CST to close these defects. He added a laparoscopic element, thereby, diminishing the wound surface. He states that autologous tissue repair like the CST should be reserved for patients in whom prosthetic repair is contraindicated, i.e. in contaminated operations, as the rate of reherniation is similar to that found after open suture repair [15]. He found wound complication rates of $33 \%$ and a recurrence rate of $32 \%$ using the CST [16].

In 2007, van Geffen also wrote a thesis about the CST for the treatment of patients with large abdominal wall defects. He modulated the CST technique and combined it with an augmenting mesh. He compared groups with and without the use of a mesh and found less recurrences in the mesh group; however, the group size was too small to be significant. The overall study treated 95 patients and they found a recurrence of $15.6 \%$ after a median follow-up of 48 months [17]. Several studies [16-19] report a recurrence rate varying from 5 to $32 \%$ after the use of CST, but most studies lack adequate study size or duration of follow-up.
A recent Cochrane analysis performed by den Hartog et al. states that there is insufficient evidence as to which type of mesh or in which position it should be used in open ventral hernia repair. Also, insufficient evidence was found to advocate the use of the CST [3].

Nevertheless, recent studies performed in Germany and the United States report good results using laparoscopic repair and a modified CST, with recurrence rates as low as $5 \%[11,19,20]$.

Conditions associated with recurrent herniation are obesity, previous abdominal aneurysm surgery, suture repair, chronic constipation, chronic obstructive airway disease, smoking and occupational lifting [21].

The wide overlap of the previously described onlay technique allows a large surface area for the in-growth of connective tissue, leading to permanent fixation within the abdominal wall. We believe that, with incisional hernias, the whole scar is insufficient and, therefore, needs to be corrected as a whole. The wide placement decreases the risk of recurrence and allows for the shrinkage of the mesh; however, this might also lead to the formation of seromas.

Complications like wound-healing disorders, seroma, haematoma and mesh removal are more common after an onlay procedure compared to other techniques [7, 9]. Seroma formation was reported in different studies [1, 7, 22] to range from 0 to $63 \%$ after open mesh repair. In our study, $28 \%$ of patients suffered seroma formation; most of them could be treated conservatively in the out-patient clinic. The high incidence of seroma formation may be caused by the extensive dissection to separate the skin and subcutaneous tissue from the fascia and the subcutaneous implantation of the large mesh. It is known that a large wound surface predisposes for seroma formation [16].

Fistula formation is reported in 3\% of cases in the literature [2]. In our study, it did not occur. This is probably due to the fact that the mesh was never placed directly on the intestines. Even when the hernia could not be closed, great caution was taken to prevent this. Omentum was then placed underneath the mesh. When the intestines were, however, injured during the operation or could not be covered, a mesh was not used. Prosthesis removal ranges from 0 to $2.5 \%$ in the literature; in our study, in only one patient the mesh had to be removed-this was due to pain.

In this study, 101 patients were included with large incisional hernias. This large cohort study evaluates the correction of incisional abdominal wall hernias and which were corrected with this particular technique. Twelve patients were excluded because of bowel injury; this, however, is not related to the correction technique but shows the challenge of performing an incisional hernia correction in this patient group. A recurrence rate of $16 \%$ was found, which is comparable to other techniques. Therefore, this technique, although it has its disadvantages, 
is very useful in repairing incisional hernias in patients who need an uncomplicated and fast surgical procedure. The advantages of the technique are a mean operation time of 63 min, no mortality and no unacceptable technical difficulties to put in the mesh. Therefore, it seems to be an effective and simple way to repair extremely large, as well as the more complicated, hernias.

Of course, the final indication for an abdominal wall correction needs to be tailored to the kind of hernia the patient has; small or large, simple or complicated.

At this moment in time, there is no gold standard available, and we even state that, for incisional hernias, there cannot be a gold standard because different types of incisional hernias and different patient groups need a different treatment approach. Perhaps a superior classification of the hernias can help to decide which therapy is best for which patient.

Dietz et al. described a classification system to subdivide different kinds of incisional hernias [23, 24]. They enlist morphology, patient body type and risk factors in the assessment of prognosis. After classifying different kinds of hernias and studying these groups separately, it might be easier to make surgical recommendations for these different groups.

Quality of life is a major endpoint in evaluating surgical techniques; however, no study concerning incisional hernia repair has included this. Therefore, we decided to score the quality of life of the patients corrected with this technique for further investigation. We will also perform a subgroup analysis of the patients whose abdominal wall was corrected after open-abdomen treatment. Subsequently, we hope to be able to make further recommendations for which patients should be operated using this technique.

\section{Conflict of interest statement None.}

Open Access This article is distributed under the terms of the Creative Commons Attribution Noncommercial License which permits any noncommercial use, distribution, and reproduction in any medium, provided the original author(s) and source are credited.

\section{References}

1. Kingsnorth A, LeBlanc K (2003) Hernias: inguinal and incisional. Lancet 362(9395):1561-1571

2. Cassar K, Munro A (2002) Surgical treatment of incisional hernia. Br J Surg 89(5):534-545

3. den Hartog D, Dur AH, Tuinebreijer WE, Kreis RW (2008) Open surgical procedures for incisional hernias. Cochrane Database Syst Rev 3:CD006438

4. Urbach DR (2005) Measuring quality of life after surgery. Surg Innov 12(2): 161-165

5. Wright JG (1999) Outcomes research: what to measure. World J Surg 23(12):1224-1226
6. Heniford BT, Walters AL, Lincourt AE, Novitsky YW, Hope WW, Kercher KW (2008) Comparison of generic versus specific quality-of-life scales for mesh hernia repairs. J Am Coll Surg 206(4):638-644

7. Luijendijk RW, Hop WC, van den Tol MP, de Lange DC, Braaksma MM, IJzermans JN et al (2000) A comparison of suture repair with mesh repair for incisional hernia. $\mathrm{N}$ Engl $\mathrm{J}$ Med 343(6):392-398

8. Burger JW, Luijendijk RW, Hop WC, Halm JA, Verdaasdonk EG, Jeekel J (2004) Long-term follow-up of a randomized controlled trial of suture versus mesh repair of incisional hernia. Ann Surg 240(4):578-583

9. Korenkov M, Paul A, Sauerland S, Neugebauer E, Arndt M, Chevrel JP et al (2001) Classification and surgical treatment of incisional hernia. Results of an experts' meeting. Langenbecks Arch Surg 386(1):65-73

10. Korenkov M, Sauerland S, Arndt M, Bograd L, Neugebauer EA, Troidl H (2002) Randomized clinical trial of suture repair, polypropylene mesh or autodermal hernioplasty for incisional hernia. Br J Surg 89(1):50-56

11. Gananadha S, Samra JS, Smith GS, Smith RC, Leibman S, Hugh TJ (2008) Laparoscopic ePTFE mesh repair of incisional and ventral hernias. ANZ J Surg 78(10):907-913

12. Barbaros U, Asoglu O, Seven R, Erbil Y, Dinccag A, Deveci U et al (2007) The comparison of laparoscopic and open ventral hernia repairs: a prospective randomized study. Hernia 11(1):5156

13. Liapis CD, Dimitroulis DA, Kakisis JD, Nikolaou AN, Skandalakis P, Daskalopoulos M et al (2004) Incidence of incisional hernias in patients operated on for aneurysm or occlusive disease. Am Surg 70(6):550-552

14. Ramirez OM, Ruas E, Dellon AL (1990) "Components separation" method for closure of abdominal-wall defects: an anatomic and clinical study. Plast Reconstr Surg 86(3):519-526

15. de Vries Reilingh TS, Bodegom ME, van Goor H, Hartman EH, van der Wilt GJ, Bleichrodt RP (2007) Autologous tissue repair of large abdominal wall defects. Br J Surg 94(7):791-803

16. de Vries Reilingh TS, van Goor H, Rosman C, Bemelmans MH, de Jong D, van Nieuwenhoven EJ et al (2003) "Components separation technique" for the repair of large abdominal wall hernias. J Am Coll Surg 196(1):32-37

17. van Geffen HJAA, Kreb D, Simmermacher RKJ, Olsman J, van der Werken Chr (2009) Long-term results of reconstructing large abdominal wall defects with the components separation method. In: Schumpelick V, Fitzgibbons RJ (eds) Recurrent hernia, pp 205-211

18. Lowe JB, Garza JR, Bowman JL, Rohrich RJ, Strodel WE (2000) Endoscopically assisted "components separation" for closure of abdominal wall defects. Plast Reconstr Surg 105(2):720-729

19. Moore M, Bax T, MacFarlane M, McNevin MS (2008) Outcomes of the fascial component separation technique with synthetic mesh reinforcement for repair of complex ventral incisional hernias in the morbidly obese. Am J Surg 195(5):575-579

20. Benhidjeb T, Benecke C, Strik MW (2008) Incisional hernia repair: sublay or intraperitoneal onlay mesh (IPOM)? Zentralbl Chir 133(5):458-463

21. Vidović D, Jurisić D, Franjić BD, Glavan E, Ledinsky M, Bekavac-Beslin M (2006) Factors affecting recurrence after incisional hernia repair. Hernia 10(4):322-325

22. de Vries Reilingh TS, van Geldere D, Langenhorst B, de Jong D, van der Wilt GJ, van Goor H et al (2004) Repair of large midline incisional hernias with polypropylene mesh: comparison of three operative techniques. Hernia 8(1):56-59

23. Dietz UA, Hamelmann W, Winkler MS, Debus ES, Malafaia O, Czeczko NG et al (2007) An alternative classification of 
incisional hernias enlisting morphology, body type and risk factors in the assessment of prognosis and tailoring of surgical technique. J Plast Reconstr Aesthet Surg 60(4):383-388
24. Winkler MS, Gerharz E, Dietz UA (2008) Overview and evolving strategies of ventral hernia repair. Urologe A 47(6):740-747 